\title{
Relapsing Polychondritis in the Department of Defense Population and Review of the Literature
}

\author{
Stephanie D. Mathew, DO, ${ }^{*}$ Daniel F. Battafarano, DO, FACP, FACR,* \\ and Michael J. Morris, MD, FACP, FCCP ${ }^{\dagger}$
}

\begin{abstract}
Objective: The objective of this study was to characterize the clinical features of relapsing polychondritis (RPC) within the Department of Defense beneficiary population and determine the utility of echocardiography, imaging studies, and pulmonary function testing for diagnosis and monitoring disease.

Methods: We performed a retrospective Electronic Medical Record chart review of all patients diagnosed with RPC within the Department of Defense between January 2004 and December 2009.

Results: Thirty patients met McAdam's diagnostic criteria and an additional 13 met our criteria for partial RPC. Auricular chondritis (88\%), inflammatory eye disease (57\%), and arthritis (60\%) were the most common clinical manifestations. Pulmonary involvement was seen in $16(37 \%)$ patients. Methotrexate $(42 \%)$ and corticosteroids $(21 \%)$ were the most conventional therapies. Thirty $(70 \%)$ patients had pulmonary function tests with flow volume loop abnormalities observed in $33 \%$. Chest computed tomography was performed in $63 \%$, with abnormalities in $48 \%$. Abnormalities on echocardiography were observed in 12 of 25 (48\%) patients.

Conclusions: The incidence, demographic data, and organ involvement in our RPC patients were similar to previous studies. The diagnosis of RPC was determined primarily on physical examination and symptom-driven diagnostic testing. There was no notable pattern by rheumatologists for monitoring the progression of tracheobronchial tree or large vessel involvement. Interpreting flow volume loops is recommended with pulmonary function testing to detect early laryngotracheal involvement. Computed tomography of the chest is also recommended to monitor for vascular and tracheobronchial tree involvement.
\end{abstract}

Published by Elsevier Inc. Semin Arthritis Rheum 42:70-83

Keywords: Relapsing polychondrities, Polychondrities

$\mathrm{R}$ elapsing polychondritis (RPC) is a rare autoimmune disorder of unknown etiology. It was first described by Jaksch-Wartenhorst in 1923 and termed polychondropathia (1); the term relapsing poly-

\footnotetext{
*Rheumatology Service, Department of Medicine, Brooke Army Medical Center, Fort Sam Houston, TX.

$\dagger$ Pulmonary Disease Service, Department of Medicine, Brooke Army Medical Center, Fort Sam Houston, TX.

Presented in part at the American College of Rheumatology (ACR)/Association of Rheumatology Health Professionals (ARHP) 2010 Annual Scientific Meeting, November 10, 2010, Atlanta, GA, USA.

Michael J. Morras is on the speakers bureau for Pfizer/Boehringer-Ingelheim. The authors have no conflicts of interest to disclose.

"The opinions in this manuscript do not constitute endorsement by Brooke Army Medical Center, the U.S. Army Medical Department, the U.S. Army Office of the Surgeon General, the Department of the Army, Department of Defense or the U.S. Government of the information contained therein."

Address reprint requests to Daniel F. Battafarano, DO, FACP, FACR, Brooke Army Medical Center, Rheumatology Service, Department of Medicine, 3851 Roger Brooke Drive, Fort Sam Houston, Texas 78209. E-mail: Daniel.Battafarano@

amedd.army.mil.
}

chondritis was coined in 1960 by Pearson and coworkers (2). The disease is characterized by episodic inflammation and destruction of cartilaginous and protean structures including the ear; eye; nose; larynx; trachea; bronchi; joints; skin; heart valves; and aorta. The auricular cartilage is classically affected; however; involvement of the tracheobronchial tree is a major cause of morbidity and mortality.

RPC occurs in individuals of all races and age groups with men and women affected equally. It appears to be more common in Caucasians and the age of onset is typically between 40 and 60 . Although the prevalence of $\mathrm{RPC}$ is unknown, the estimated incidence based on demographics from Rochester, $\mathrm{MN}$ is reported at 3.5 cases/ million (3). Approximately $30 \%$ of patients have a concomitant connective tissue disease or malignancy (4).

The diagnosis is based on compatible clinical features, laboratory data, and occasionally biopsy of involved cartilage. Disease monitoring is usually symptom driven and 


\begin{tabular}{|c|c|c|}
\hline McAdam's Criteria (5) & Damiani and Levine (7) & Michet's Criteria (6) \\
\hline $\begin{array}{l}\text { Clinical features: } \\
\text { Bilateral auricular chondritis } \\
\text { Nonerosive, seronegative } \\
\text { inflammatory polyarthritis } \\
\text { Nasal chondritis } \\
\text { Ocular inflammation } \\
\text { Respiratory tract chondritis } \\
\text { Cochlear or vestibular dysfunction } \\
\text { or both }\end{array}$ & $\begin{array}{l}3 \text { clinical features } \\
\text { One clinical feature and histologic } \\
\text { evidence of chondritis } \\
\text { Chondritis at } 2 \text { or more separate } \\
\text { anatomic locations with response to } \\
\text { corticosteroids, dapsone, or both }\end{array}$ & $\begin{array}{l}\text { Major criteria: } \\
\text { Proven inflammatory episodes involving } \\
\quad \text { auricular cartilage } \\
\text { Proven inflammatory episodes involving } \\
\text { nasal cartilage } \\
\text { Proven inflammatory episodes involving } \\
\quad \text { laryngotracheal cartilage } \\
\text { Minor criteria: } \\
\text { Ocular inflammation } \\
\text { Hearing loss } \\
\text { Vestibular dysfunction } \\
\text { Seronegative inflammatory arthritis }\end{array}$ \\
\hline $\begin{array}{l}\text { Diagnosis: } \\
3 \text { clinical features }\end{array}$ & $\begin{array}{l}\text { Diagnosis: } \\
3 \text { McAdam criteria } \\
1 \text { McAdam criteria and histology } \\
2 \text { McAdam criteria and response to } \\
\text { corticosteroids or dapsone }\end{array}$ & $\begin{array}{l}\text { Diagnosis: } \\
2 \text { major criteria } \\
1 \text { major criteria plus } 2 \text { minor criteria }\end{array}$ \\
\hline
\end{tabular}

may involve echocardiography, pulmonary function testing, or imaging of the neck and chest. The current treatment of RPC is not standardized and is influenced by the extent and type of organ involvement. Isolated auricular involvement may respond to nonsteroidal anti-inflammatory medications alone, whereas patients with cardiac and pulmonary manifestations may require high-dose corticosteroids initially followed by disease-modifying anti-rheumatic drugs (DMARDs) or biologic agents as maintenance therapy.

This retrospective review was undertaken after a patient with 2 years of recurrent episodes of dyspnea and abnormal flow volume loop on pulmonary function tests (PFTs) was discovered to have RPC. This index case prompted a search within our patient population for typical clinical features and monitoring patterns practiced by rheumatologists. The purpose of this study was to characterize the clinical features of RPC within the Department of Defense (DoD) patients and to determine the utility of echocardiography, imaging studies, and pulmonary function testing for diagnosis and monitoring the disease.

\section{MATERIALS AND METHODS}

We performed a retrospective electronic medical record (EMR) review, with approval by the Brooke Army Medical Center Institutional Review Board, for all patients diagnosed with RPC, within the DoD beneficiary population between January 2004 and December 2009. The International Classification of Diseases, ninth Revision (ICD-9) diagnostic code, 733.9 polychondritis (atrophic, chronic, relapsing), was used to search the centralized DoD database to identify these patients. During the specified years, the beneficiary patient base was approximately 9.5 million people. Patients were included if they met
McAdam's diagnostic criteria for RPC (Table 1) (5-7) or if they had partial RPC manifested by recurrent chondritis with deformity, plus vestibular dysfunction, ocular inflammation, or inflammatory arthritis. The criteria for partial RPC were developed as many patients did not meet current diagnostic criteria, did not fit into other disease categories, and clinically responded to therapies. Demographic information, disease duration, organ involvement, treatment history, imaging studies, echocardiography, and PFTs were recorded for analysis.

An Ovid search was performed from 1996 to November 2011 using the keywords "Relapsing Polychondritis"+ "therapy" or "drug therapy", "English language" and "Human". This search yielded 130 articles. Twelve articles were excluded as the primary focus of the article was surgical intervention; 22 were excluded as they addressed overlap diseases or were not RPC. Fifty-eight were excluded as they did not sufficiently address treatment (the primary focus was imaging techniques or unique presentations), and 1 article did not address human subjects. Thirty-seven total articles were reviewed for pattern of organ involvement, medications administered, and outcomes. Eighteen of the articles reviewed biologic agents; 7 addressed DMARD therapy, colchicine, or indomethocin, and 12 articles provided a general overview of treatment.

\section{Index Case}

A 42-year-old Caucasian woman presented in October 2004 with hoarseness, intermittent aphonia, and dyspnea. Her past medical history was only significant for hypothyroidism. She was empirically treated for an upper respiratory tract infection and gastroesophageal reflux disease (GERD) by her primary care physician. When her symptoms failed to remit with these therapies, she was referred to otolaryngology in 2005 . On her initial visit 
with otolaryngology, a flexible laryngoscopy showed erythema and edema of the vocal cords as well as subglottic edema (Fig. 1). Laboratory evaluation revealed an elevation of the erythrocyte sedimentation rate (ESR) $(40 \mathrm{~mm} /$ $\mathrm{h}$ ), and negative antinuclear antibody, rheumatoid factor, and antineutrophilic cytoplasmic antibody (ANCA). Following unsuccessful treatment by speech therapy, she was evaluated by an allergist. She had negative skin testing and a trial of antihistamines and nasal steroids were ineffective. Her symptoms remained unchanged and she was referred to gastroenterology to assess for chronic GERD as an etiology for her symptoms. An upper endoscopy and a $\mathrm{pH}$ probe were both unremarkable. In January 2007, the patient was seen by the pulmonary service. PFTs (Fig. 2) showed a pattern of fixed airway obstruction. She was diagnosed with vocal cord dysfunction. She was evaluated multiple times in the emergency department for acute shortness of breath because of vocal cord dysfunction or asthma. When she received corticosteroids for these episodes, her clinical symptoms dramatically improved. In May 2007, a computed tomography (CT) scan showed subglottic stenosis extending from the vocal cords to the bottom of cricoid cartilage with an anterior posterior diameter of 4 to $5 \mathrm{~mm}$ (Fig. 3). Laser dilation was performed and biopsies of the tracheal cartilage, taken concomitantly, only demonstrated inflammation of the mucosa. Cultures for fungus, acid-fast bacilli, and other bacteria were negative. PFTs following the intervention showed resolution of the fixed airway obstruction (Fig. 4). One week later, she was referred to rheumatology. On the initial visit, the patient reported a history of intermittent nasal bridge pain with associated epistaxis and a change in the shape of the dorsum of her nose. She also complained of intermittent pain of her pinna over the preceding months and recurrent erythema of the conjunctiva.

The rheumatology examination was notable for mild collapse of the nasal cartilage. A clinical diagnosis of RPC was established based on history and physical examination. Oral corticosteroids $(1 \mathrm{mg} / \mathrm{kg} / \mathrm{d})$ were initiated with

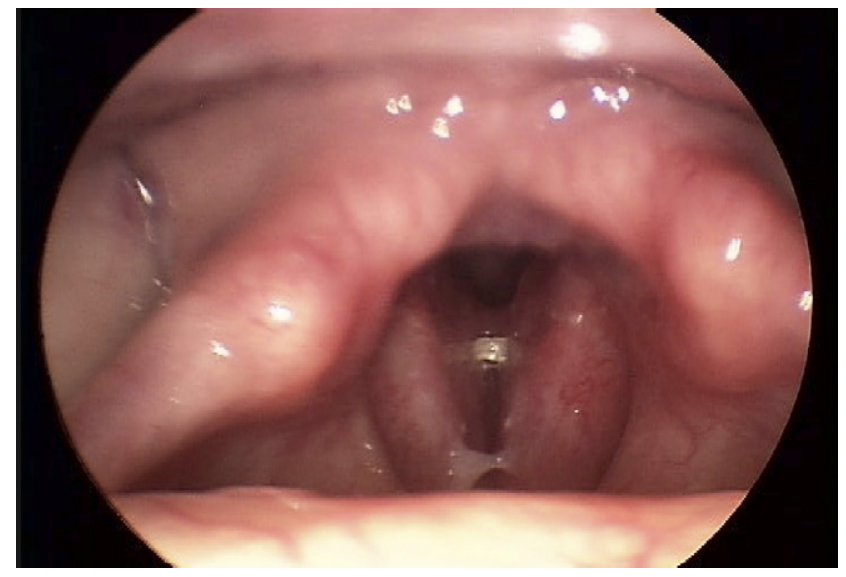

Figure 1 Fiberoptic laryngoscopy showing vocal cord and glottis erythema, edema, as well as arytenoid cartilage edema. (Color version of figure is available online.)

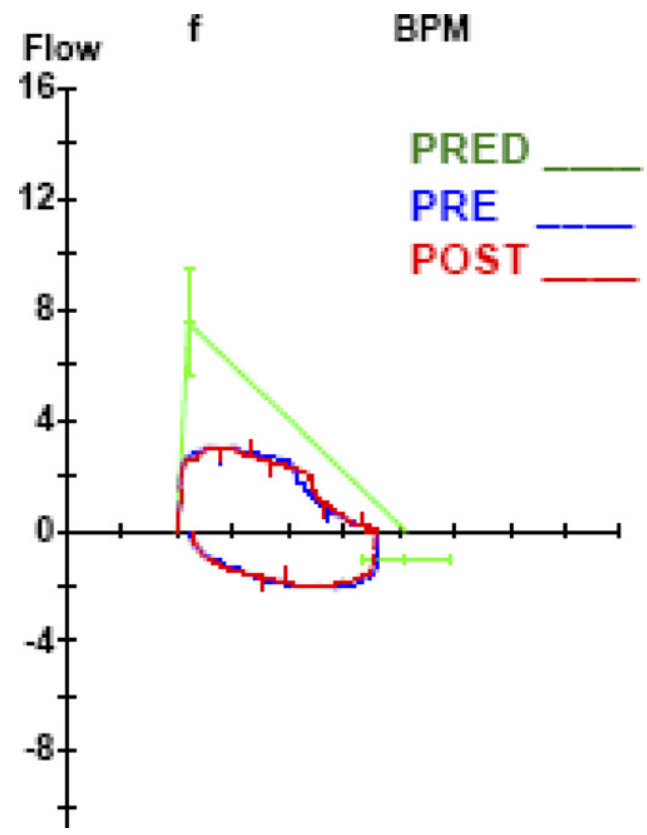

Figure 2 A flow volume loop recorded during the spirometry examination on this patient. The area above the $X$ axis represents expiratory flow and the area below the $X$ axis represents inspiratory flow. Flattening or truncation of both the expiratory and the inspiratory curves suggests a fixed airway obstruction that does not vary with respiration. (Color version of figure is available online.)

resolution of her ear pain, epistaxis, and hoarseness after 4 weeks of therapy. Oral methotrexate, titrated up to 17.5 $\mathrm{mg}$, was added as a steroid-sparing agent. She did well for 2 years until symptoms of worsening dyspnea and wheezing developed. A laryngoscopy showed subglottic narrowing with an elevated ESR $(95 \mathrm{~mm} / \mathrm{h})$ and C-reactive protein $(9.3 \mathrm{mg} / \mathrm{dL}$, normal $<0.49 \mathrm{mg} / \mathrm{dL})$. Laser incision, local corticosteroid injection, and dilation resulted in immediate improvement in her symptoms. Adalimumab ( $40 \mathrm{mg}$ subcutaneously every other week) was added to methotrexate and the patient has remained in remission.

This case represents an example of RPC presenting with laryngotracheal disease clinically mimicking asthma

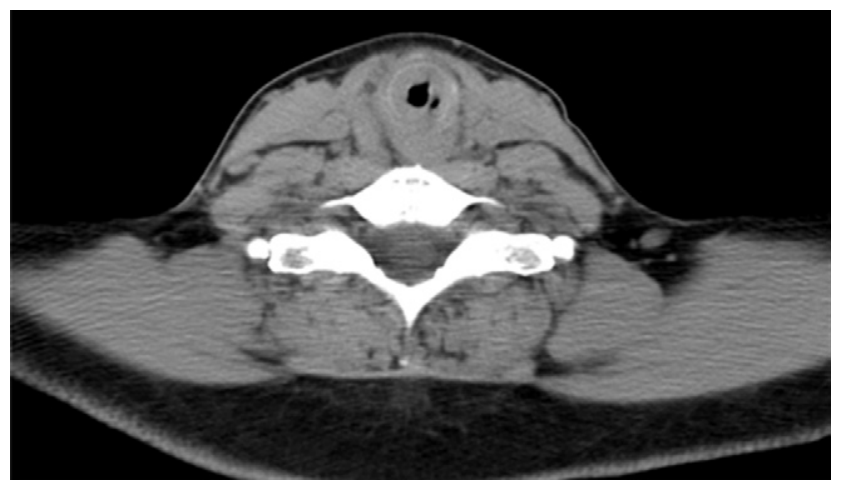

Figure 3 CT NECK without contrast demonstrates subglottic stenosis at a level $3 \mathrm{~cm}$ above the carina. 
or GERD until the development of more classic ear and nose manifestations. This case highlights the common delay in diagnosis in patients with RPC but also the classic PFT signs of extrathoracic obstruction on the flow volume loop curves with early upper airway involvement.

\section{RESULTS}

There were 50 patients diagnosed with RPC in the DoD between January 2004 and December 2009 based on the EMR. These 50 charts were reviewed and 43 patients met the study inclusion criteria. Thirty patients met McAdam's diagnostic criteria and an additional 13 met criteria for partial RPC. Seven patients were excluded, as the patients were erroneously identified on a single visit as having RPC. Of the 7 excluded patients, 1 had biopsy-proven Wegener's granulomatosis, 1 had trauma to the auricular cartilage, 3 had otitis externa, and 1 had varicella zoster infection.

\section{Demographics}

The demographic information is shown in Table 2. Twenty-three $(53 \%)$ of the patients were women with a mean age of 51 (range, 13 to 80). There were 2 cases of childhood-onset RPC. The average age at diagnosis in the adult population was 44 (range, 22 to 69) and 9.5 in the pediatric cases. The average disease duration was 7.1 years (range, 1 to 34). The mean time to diagnosis was 3.2 years with a range from 1 month to 9 years. The calculated prevalence of RPC in our population was 4.5 per million.

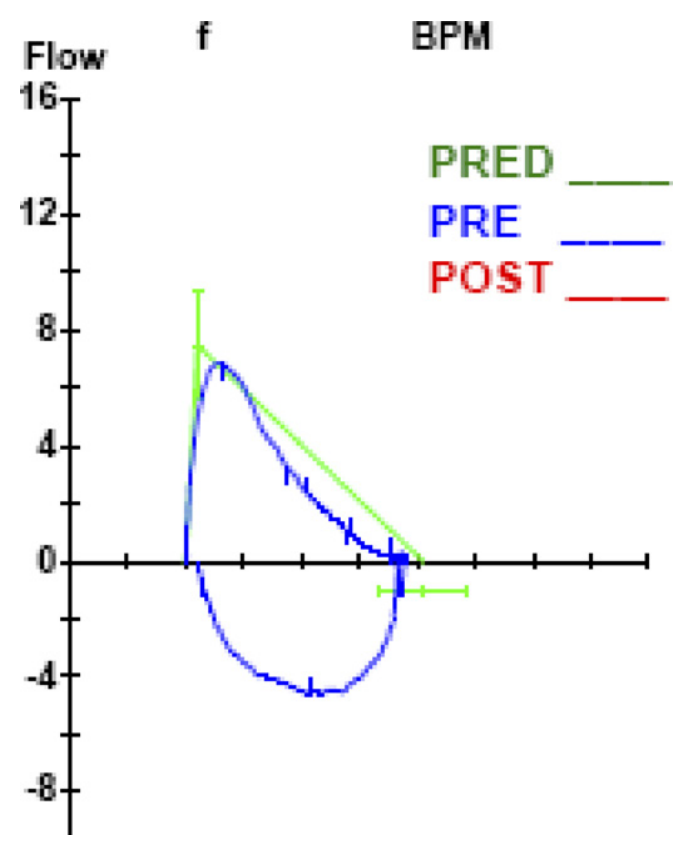

Figure 4 The post treatment flow volume loop demonstrates normal findings with resolution of both inspiratory and expiratory abnormalities related to the upper airway obstruction. (Color version of figure is available online.)

\begin{tabular}{|ll|}
\hline Table 2 Demographic Information & \\
\hline \multicolumn{1}{|c|}{ Demographic Information } & $\begin{array}{c}\text { Number of Patients } \\
(n=43)(\%)\end{array}$ \\
\hline Female & $23 / 43(53 \%)$ \\
Race (not available on all & $25 / 36(69 \%)$ \\
individuals) & Caucasian \\
Mean age & 51 (range 13-80) \\
Mean age at diagnosis & 43 (range 6-69) \\
Disease duration (yr) & 7.1 (range 1-34) \\
Average time to diagnosis (yr) & 3.2 \\
Prevalence of disease & 4.5 per million \\
\hline
\end{tabular}

\section{Organ Involvement}

The frequency of clinical manifestations is summarized in Table 3. Auricular chondritis was the most common feature in $38(88 \%)$ patients. Inflammatory arthritis was present in $26(60 \%)$ patients. Inflammatory eye disease, including episcleritis, scleritis, and conjunctivitis, were seen in 23 (57\%). Laryngotracheal involvement as demonstrated by symptoms of hoarseness, dysphonia, dyspnea, wheezing, or cough, radiographic findings, or PFT abnormalities were seen in $16(37 \%)$. Sensorineural hearing loss on audiogram was noted in $16(37 \%)$. Nasal chondritis was reported in $15(35 \%)$ and keratoconjuntivitis in 7 (16\%). Two patients with biopsy-proven RPC had vasculitis; 1 presented with renal insufficiency, hematuria, and proteinuria, and 1 presented with diffuse alveolar hemorrhage. Eleven (26\%) patients had a concomitant autoimmune/connective tissue disease including 2 rheumatoid arthritis (RA), 3 systemic lupus erythematosus (SLE), 1 myositis, 1 mixed connective tissue disease, 2 ulcerative colitis, 1 sarcoidosis, and 1 hypothyroidism.

\section{Diagnostic Evaluations}

Thirty (70\%) patients had PFTs with spirometry, 18 with reviewable flow volume loops (FVLs). FVL abnormalities

\begin{tabular}{|lc|}
\hline \multicolumn{2}{|c|}{ Table 3 Organ Involvement in RPC Patients } \\
\hline \multicolumn{1}{|c|}{ Disease Manifestation } & Number of Patients (\%) \\
\hline Auricular chondritis & $38(88 \%)$ \\
Inflammatory arthritis & $26(60 \%)$ \\
Inflammatory eye disease & $23(57 \%)$ \\
Concomitant connective tissue & $11(26 \%)^{\mathrm{a}}$ \\
disease & $16(37 \%)$ \\
Laryngotracheal involvement & $16(37 \%)$ \\
Sensorineural hearing loss & $15(35 \%)$ \\
Nasal chondritis & $7(16 \%)$ \\
Keratoconjunctivitis & $2(4.7 \%)$ \\
Vasculitis & $1(2.3 \%)$ \\
Renal involvement & 1 mixed connective \\
\hline aEleven (26\%) patients had a concomitant autoimmune/connec- \\
tive tissue disease including 2 rheumatoid arthritis (RA), 3 sy- \\
temic lupus erythematosis (SLE), 1 myositis, 1 colis, 1 sarcoidosis, and 1 \\
tissue disease (MCTD), 2 ulcerative colitis \\
hypothyroidism.
\end{tabular}


were observed in 6 of 18 patients (33\%). Eighty-three percent $(5 / 6)$ of these patients exhibited upper respiratory symptoms, primarily hoarseness. Chest CT was performed in $27(63 \%)$ and in 5 of 6 patients with FVL abnormalities. Pulmonary CT abnormalities were described in $13(48 \%)$ patients as parenchymal lung disease (9), tracheal abnormalities (4), and enlargement of the great vessels (2). Echocardiographic abnormalities in 12 of $25(48 \%)$ revealed aortic regurgitation, aortic stenosis, mitral regurgitation or mitral stenosis (8), aortic root dilatation (3), and pericarditis (1).

\section{Medical Therapy}

Methotrexate was used in 18 (42\%), corticosteroids in 13 (21\%), nonsteroidal anti-inflammatory drugs (NSAIDs) in $10(23 \%)$, other DMARDs (mycophenolate mofetil, azathioprine, hydroxychloroquine) in 8 (18\%), biologics (adalimumab, infliximab, etanercept or rituximab) in 7 $(16 \%)$, and dapsone in $4(9 \%)$. Twenty $(47 \%)$ patients required multiple medications. Thirteen of the patients in our series were maintained on dapsone or NSAIDs with an occasional burst of corticosteroids for flares. Two patients were treated with Plaquenil alone, primarily for auricular chondritis. Methotrexate was added in 18 patients as a second-line agent with recalcitrant chondritis, iritis, or tracheal involvement. Eight of these 18 patients were maintained on methotrexate monotherapy with a significant decrease in flares. However, 10 of the 18 were either intolerant or flaring through methotrexate. In 3 of these 10 patients mycophenolate mofetil was added/substituted; in 4 azathioprine was the next drug of choice, and the remaining 3 cases received a biologic. Three patients required a combination of DMARDs, biologic, and corticosteroids to control disease activity; 2 of these patients had tracheal involvement and 1 had vasculitis.

\section{DISCUSSION}

$\mathrm{RPC}$ is a rare autoimmune disease characterized by recurrent inflammation of cartilaginous structures. The disease frequently presents with a sudden onset, although the presenting features are variable. The clinical manifestations and biopsy findings of this disease were first classified by McAdam and colleagues (5); the criteria for diagnosis have been modified to accommodate different presentations of disease and limit the need for biopsy (Table 1). McAdam's clinical features include bilateral auricular chondritis, nonerosive inflammatory arthritis, nasal chondritis, ocular inflammation, respiratory tract chondritis, or vestibular dysfunction. McAdam's requires 3 of the clinical features to be present for diagnosis (5). Damiani and Levine broadened McAdam's criteria in 1979 to include histology and clinical response to steroids or dapsone (7). Typical histologic findings of affected cartilage include lymphocyte infiltration with invasion of granulation tissue and loss of the normal basophilia. The diagnosis is confirmed if 3 clinical features are present, 1 clinical feature with characteristic histology, or chondritis at 2 separate locations responsive to steroids or dapsone (7).

In 1986 Michet further divided the clinical findings into major criteria (inflammation of the auricular, nasal, or laryngotracheal cartilage) and minor criteria (ocular inflammation, hearing loss, vestibular dysfunction, seronegative inflammatory arthritis). Diagnosis is made by the presence of 2 major plus 1 minor or 1 major plus 2 minor criteria (6).

Although the most widely accepted diagnostic criteria are those put forth by both Michet et al. (6), as well as Damiani and Levine $(7,10)$, these will fail to diagnose those patients with isolated auricular chondritis in the absence of infection. Subsequently, the diagnosis of RPC must be kept within the differential diagnoses of those patients presenting with isolated auricular chondritis, which fails to respond to antibiotic therapy.

\section{Clinical Manifestations Otologic Manifestations}

Otologic disease is common in RPC and can involve the outer, middle, and inner ear. Auricular chondritis is the presenting feature in $43 \%$ of cases and is eventually seen in $89 \%$ of patients according to literature review (3). It is classically characterized by erythema, warmth, swelling, and tenderness of the helix, antihelix, tragus, or antitragus with sparing of the noncartilaginous ear lobe (Fig. 5). Attacks usually last several days and may resolve spontaneously. Prolonged or recurrent attacks can result in irreversible cartilage damage resulting in drooping of the pinna or "cauliflower ear" (Fig. 6).

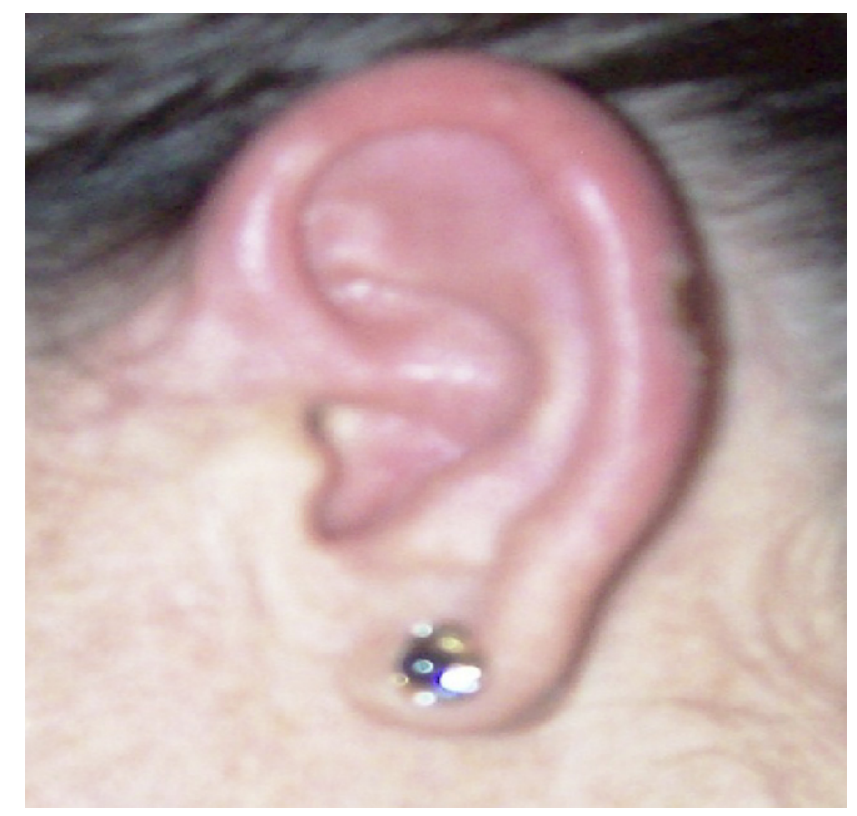

Figure 5 Auricular chondritis with sparing of the noncartilaginous ear lobe. (Color version of figure is available online.) 


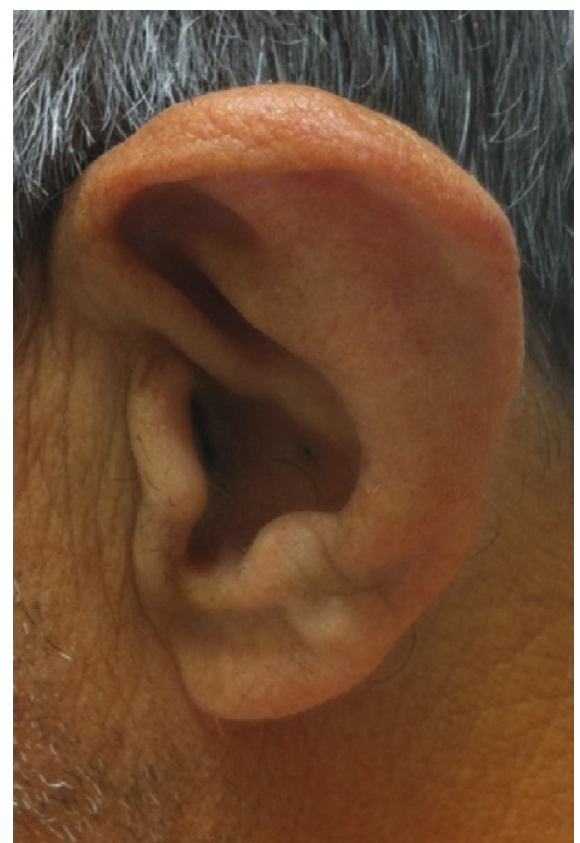

Figure 6 Cartilage destruction following repeated episodes of auricular inflammation. (Color version of figure is available online.)

Conductive hearing loss develops in up to $46 \%$ of patients and sensorineural hearing loss and vestibular dysfunction (vertigo, dizziness) can occur. Conductive hearing loss can be secondary to (1) cartilage destruction with closure of the external auditory meatus, (2) eustachian tube obstruction, or (3) serous otitis media $(8,9)$. The etiology of sensorineural hearing loss and vestibular dysfunction may be due to either vasculitis of the branches of the internal auditory artery (4) or autoantibodies against labyrinthine binding sites with a local inflammatory response and subsequent apoptosis of labyrinthine cells (10).

\section{Nasal Chondritis}

Nasal chondritis is the presenting feature in 21\% of patients and will develop over the course of the disease in $61 \%$ (3). This is typically sudden in onset and characterized by swelling and tenderness of the distal part of the nasal septum. Patients can manifest with nasal crusting, rhinorrhea, or mild epistaxis. Recurrent or prolonged episodes can lead to cartilage collapse resulting in a saddle nose deformity (Fig. 7).

\section{Ocular Manifestations}

Ocular inflammation occurs in $18 \%$ of patients at presentation and in 59\% over the disease course (3). Ocular disease usually parallels other features of $\operatorname{RPC}(4,9)$. Episcleritis, scleritis (diffuse anterior), and keratitis occur in $30 \%$ of affected patients (9). Uveitis occurs in up to $25 \%$ of patients and is usually anterior or sclerouveitis (4). Peripheral ulcerative keratitis is seen in $10 \%$ of patients and can lead to rapid visual loss and corneal melt; this is a reliable clinical marker for the presence of systemic vasculitis $(4,9)$.

Proptosis with periorbital lid edema is common and is caused by posterior inflammation of the globe (9). Extraocular muscle palsies and ischemic optic neuropathy have been reported and are likely caused by a vasculitis of vessels supplying the involved muscles or associated nerves $(4,9)$. Keratoconjunctivitis sicca, salmon patch conjunctival lesion, and optic neuritis can occur with RPC (4).

\section{Laryngotracheal/Pulmonary Disease}

Airway involvement represents the most serious clinical manifestation of RPC and portends a poor overall prognosis $(11,12)$. A review by Eng and Sabanathan in 1991 only identified 62 cases reported in the literature (13). Ernst et al. in 2009 identified a prevalence of airway involvement in 31 patients $(21 \%)$ in their retrospective case series and literature review; airway symptoms were the initial manifestation in 17 of these patients (12). Others have noted respiratory tract involvement as a presenting feature in 14 to $38 \%$ of cases and may be a clinical feature in up to $67 \%$ of patients throughout the course of their disease (14). Involvement of the upper airway, particularly subglottic disease, seems more common in women $(3,13)$.

Clinical findings of airway involvement may range from asymptomatic in early disease to dyspnea, cough, stridor, and hoarseness $(12,13)$. Other reported symptoms may include choking, wheezing, aphonia, or tenderness over the tracheal or anterior thyroid cartilage (14). Involvement of the glottis, subglottic area, or upper tra-

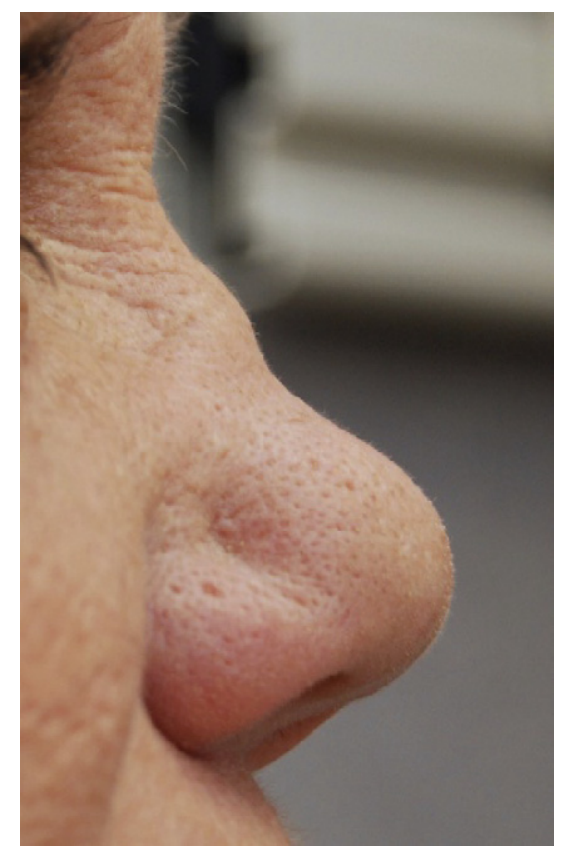

Figure 7 Image showing "saddle" nose deformity following recurrent nasal cartilage inflammation. (Color version of figure is available online.) 
chea is always symptomatic, whereas lower airway or bronchial involvement may be asymptomatic (11). Tracheobronchomalacia can occur because of repeated bouts of inflammation with loss of cartilaginous support structure, dynamic collapse of the airways, and potentially postobstructive pneumonia or collapse of distal airway disease. Other rare presentations include isolated distal airway involvement, or costochondral involvement leading to dislocation and flail chest and sudden tracheal collapse with respiratory arrest $(9,11,15)$.

Plain radiography of the airway to include lateral neck films and standard chest radiography is recommended in all patients with RPC. Imaging may identify tracheal narrowing, calcification of the tracheal or laryngeal cartilages, infiltrates, atelectasis (possibly caused by obstruction), and pulmonary edema. CT of the chest performed at end inspiration can demonstrate fixed airway narrowing, thickening of the anterior, and lateral cartilaginous tracheobronchial wall $(>2 \mathrm{~mm})$ with sparing of the membranous posterior wall. Dynamic expiratory CT scan (performed during forceful exhalation) helps to identify functional airway abnormalities including tracheobronchomalacia and air trapping (16). Dynamic expiratory CT demonstrated abnormalities in 94\% of the study population, whereas abnormalities on end-inspiratory CT were found in only $44 \%$ (17). Tracheobronchomalacia is seen in $63 \%$ of patients during dynamic expiratory CT scanning (12).

Magnetic resonance imaging (MRI) is superior to CT in distinguishing between fibrosis, inflammation, and edema of the trachea. Long-standing fibrosis will appear dark on T1 and T2 images and have minimal enhancement with the administration of contrast. Conversely, inflammation will appear hyperintense on T2 images and will enhance with the administration of gadolinium of T1 images (18).

Fiberoptic bronchoscopy may be a useful adjunct in the examination of the airway primarily for evidence of obstruction or collapse. Reported findings may include subglottic stenosis, tracheal and bronchial stenoses, thickening and calcifications of the airway walls, tracheobronchomalacia, or evidence of dynamic airway collapse not identified during CT imaging.

Pulmonary function testing. Expert opinion has recommended that PFTs to include FVL should be performed in all patients with RPC to detect asymptomatic disease and help characterize airway obstruction in symptomatic patients. The combination of spirometry with FVL and the measurement of airway resistance may be a better measurement than bronchoscopy and radiography in detecting the presence, severity, and nature of airway obstruction in RPC $(19,20)$. However, there are limited data on the comparison of modalities because both studies are based on small numbers of RPC patients. The largest cohort of 31 patients in the Ernst study did not mention the results of PFTs or FVL testing (12). Spirometric findings may demonstrate obstructive indexes based on the extent and location of disease. Flow volume loops need to be carefully examined for evidence of (1) variable intrathoracic obstruction (flattening or truncation of the expiratory limb) indicative of lower tracheobronchial disease; (2) variable extrathoracic obstruction (flattening or truncation of the inspiratory limb) suggestive of upper airway disease, either the larynx or the upper trachea; or fixed airway obstruction (flattening of both limbs) indicative of a fixed airway defect (Fig. 2). Serial PFT measurements in $1 \mathrm{RPC}$ case report demonstrated temporary normalization of PFTs with early inflammatory laryngotracheal disease following immunosuppressive therapy (21).

Monitoring. We recommend PFTs with FVLs and plain radiographs of the neck/chest at baseline and with new symptoms suggestive of laryngotracheal involvement. If abnormalities are initially present, then further imaging with CT scan or MRI (if isolated tracheal involvement is suspected) is warranted to evaluate the location and extent of disease. Despite recommendations for screening for airway disease in RPC patients, $70 \%$ of our patients had PFTs at baseline and only one-third had reviewable FVL in their EMR.

\section{Cardiovascular Manifestations}

The prevalence of cardiovascular involvement in RPC ranges from $14 \%$ to $52 \%$ of patients $(3,4,22)$. Clinical manifestations include vasculitis, valvular regurgitation (mitral, aortic), aneurysm formation, arterial or venous thrombosis, conduction abnormalities, pericarditis, myocarditis, and myocardial infarction.

Vascular disease. Vascular disease can develop independently of cardiac involvement (23) and encompasses both dilatation and inflammation. Vasculitis can be a presenting feature in $2 \%$ of cases and is found during the course of disease in 14\% (3). Involvement of vessels of all sizes has been described; however, large vessel disease is most often reported. The disease can be either focal or diffuse and the presentation can range from indolent to rapidly fatal $(3,23)$. Aneurysm formation is thought to be partially due to indolent vasculitis. The most common area of aneurysm involvement is the aorta, developing in 5 to $7 \%$ of patients (23). Involvement of the ascending aorta can result in aortic valve regurgitation. Vascular dilation is also described in the descending aorta, iliac, femoral, subclavian, and abdominal vasculature, as well as the coronary and cerebral vessels (23). Although aneurysms tend to be asymptomatic, the risk for rupture remains a concern and routine screening is recommended.

Valvular disease. Valvular disease is typically not a presenting feature of RPC but can develop over time in $12 \%$ 
of patients (3). The aortic valve is most commonly affected, followed by the mitral valve. Valvular regurgitation may result from dilation of the aortic root or mitral annulus or from valvular thickening with myxomatous degeneration (22). Disease progression is insidious and requires periodic monitoring with echocardiography.

Conduction abnormalities. Atrioventricular conduction abnormalities including blocks and tachyarrythmias have been reported in 4 to $6 \%$ of patients (23). Conduction abnormalities can be due to aortic root dilatation, acute inflammation, or fibrosis of the conduction system. Often temporary pacing is required for higher degree atrioventricular blocks but there have been case reports of resolution with corticosteroid therapy $(23,24)$.

Monitoring. Early detection of cardiac involvement is important and current recommendations for evaluation include cardiac auscultation, routine electrocardiograms (EKG), chest radiographs, and echocardiography (22). A baseline evaluation of the aorta is recommended with either CT, MRI of the chest, or transesophageal echocardiography. In patients who have undergone surgery, repeat imaging is recommended every 6 months (22).

In our case series, $48 \%$ of the patients were evaluated with echocardiography; $70 \%$ had standard chest radiography, and $63 \%$ underwent chest CT. We were unable to determine the percentage of patients evaluated by EKG because this was not recorded in our EMR.

\section{Renal Manifestations}

A retrospective study of renal involvement in RPC was performed at the Mayo Clinic from 1943 to 1984 and the prevalence was found to be $22 \%$ (24). Renal involvement tends to occur in older individuals with severe disease and is associated with an increased incidence of systemic vasculitis, arthritis, and mortality (25). The etiology of renal involvement may be due to RPC or another concomitant autoimmune disorder such as SLE. The most common pathologic lesion on biopsy is mesangial cell proliferation. IgA nephropathy, tubulointerstitial nephritis, and segmental necrotizing crescentic pauci-immune glomerulonephritis have also been reported (24).

\section{Joint Involvement}

Inflammatory arthritis is present in $32 \%$ of patients at the time of diagnosis and eventually develops in $72 \%$ (3). The classic arthritis is migratory, polyarticular, asymmetrical, and nonerosive. The joints most commonly affected include the metacarpophalangeal, proximal interphalangeal, wrist, knee, ankle, sternoclavicular, and sternomanubrial. Patients are usually seronegative and any associated joint effusions tend to be noninflammatory $(5,46)$. Coexisting RA or spondyloarthropathies may complicate the diagnosis and influence medical therapy.

\section{Dermatologic Manifestations}

Dermatologic manifestations precede the development of chondritis in $12 \%$ of cases, occur concomitantly with $\mathrm{RPC}$ in $35 \%$ of cases (26), and are present overall in up to $50 \%$ of patients (4). The most common cutaneous manifestation is oral aphthosis, followed by erythema nodosum-like nodules, and purpura. Other less common presentations include sterile pustules, superficial phlebitis, purpura, skin ulcerations, papules, distal necrosis, and erythema elevatum diutinum (26). Interestingly, the frequency of mucocutaneous disease may be higher in patients diagnosed with RPC and concomitant myelodysplastic syndrome (26). Although cutaneous involvement in RPC is common, it is nonspecific and may be related to an associated autoimmune disorder.

\section{Nervous System Involvement}

Peripheral and central nervous system (CNS) involvement only occurs in 3\% of RPC patients during the disease course (3). Cranial nerve involvement is most often seen with the second, sixth, seventh, and eighth cranial nerves being affected. Other reports of peripheral nervous system involvement include hemiplegia, ataxia, myelitis, and polyneuritis. Although CNS involvement is uncommon, there have been reports of aseptic meningitis, meningoencephalitis, encephalitis, ischemic stroke, seizures (focal and generalized), confusion, hallucinations, headache, and cerebral aneurysm $(27,28)$. The pathogenesis of neurologic involvement is thought to be secondary to vasculitis. This has been corroborated on autopsy studies demonstrating diffuse vasculitis of small arteries and arterioles (29). MRI of the brain also supports vasculitis as an etiology, typically showing areas of multifocal gray and white matter enhancement (29).

\section{Pregnancy and RPC}

There was a single pregnancy in our case series. The patient had recurrent auricular chondritis, and conductive hearing loss managed with Celecoxib prior to conception. She did not flare during the pregnancy and delivered a healthy baby. In a retrospective review series, Papo et al. describe 11 patients with 25 pregnancies. Five patients suffered from 5 different associated connective tissue diseases (SLE, mixed connective tissue disease, RA, ankylosing spondylitis, and Takayasu arteritis). A flare of the RPC occurred in 7 of the pregnancies. Flares were primarily manifested by ocular disease or chondritis. Patients were managed with steroids, NSAIDs, dapsone, or plasma exchange. Ten of the pregnancies were complicated by ectopic implantation (3), spontaneous abortion (3), premature rupture of membranes (1), and premature births (3). There was 1 elective abortion and 18 live births. None of the 18 babies had neonatal inflammatory chondritis (30). 


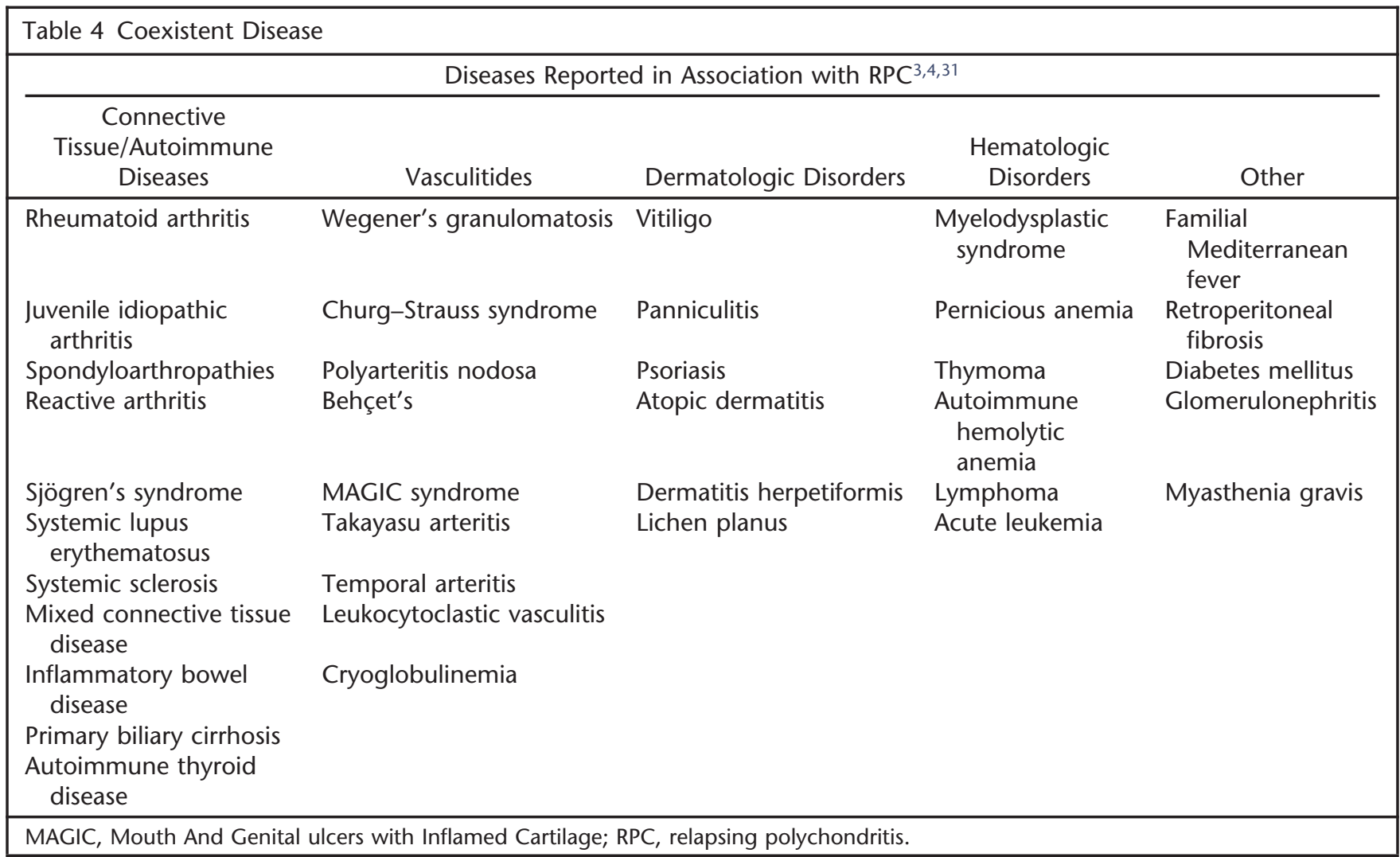

\section{Coexistent Disease}

A concomitant autoimmune disease, connective tissue defect, hematologic disorder, vasculitis, or dermatologic disease is found in 30 to $50 \%$ of patients with $\operatorname{RPC}(3,4,31)$. Table 4 includes a list of diseases that have been reported in association with RPC.

\section{Etiology and Pathogenesis}

Although the pathogenesis of RPC is unknown, there appears to be a combination of factors including genetic susceptibility, an inciting event (either chemical or traumatic), and the presence of autoimmunity. The presence of genetic susceptibility is supported by an increase in the frequency of human leukocyte antigen (HLA)-DR4 in patients with RPC $(3,32)$. HLA-DR4 is found in $56 \%$ of RPC patients compared with $26 \%$ in healthy controls (8). The allele $\mathrm{DRB}^{*} 0421$ was described in a single patient with RPC and may represent a susceptibility factor for RPC (33). A study of the HLA class II distribution of alleles among Caucasian RPC patients found $\mathrm{DQB} 1{ }^{*} 0601$, DQA $1 * 0103$, and DQA ${ }^{*} 0301$ to be significantly increased (34). An association between HLA-DR6 with patient age and type and extent of organ involvement has also been reported but the significance requires further study (8).

The evidence to support involvement of humoral and cell-mediated immunity in the pathogenesis of RPC includes the formation of autoantibodies, overlap with other connective tissue and autoimmune disorders, the presence of CD4 cells on biopsy of involved cartilage, cytokine profiles, and improvement with immunosuppressive medications.

The predilection of RPC to damage cartilaginous structures suggests the presence of autoantibodies against this tissue. The composition and location of cartilage are important in the pathogenesis and formation of autoantibodies in RPC. Chondrocytes contain many epitopes capable of eliciting an immune response. Because of the nature of cartilage (lack of vascular and lymph flow) and conformational structure, these epitopes are typically hidden from the immune system and some preceding event likely triggers their exposure. Anticollagen (type II, IX, and XI) and matrillin-1 antibodies have been reported in up to $60 \%$ of patients with RPC and tend to correlate with disease severity (9,35-37). Type-II collagen in the adult is present at 2 sites: cartilage matrix and vitreous of the eye. Type-IX collagen functions to anchor type-II collagen fibrils to the extracellular matrix and type-XI collagen regulates collagen fibril size and distribution. Matrillin-1 is a component of the extracellular matrix of cartilage within the trachea. Although it is thought that anti-type-II collagen antibodies are secondary to cartilage destruction, there is evidence in animal models suggesting an active role in RPC. In 1981, Cremer et al. injected bovine type-II collagen into 88 rats, $14 \%$ of which developed auricular chondritis, which on biopsy resembled human relapsing polychondritis (38). Furthermore, Hansson and coworkers demonstrated that cartilage components were immunogenic with the immunization of rats with matril- 
lin-1 resulting in inspiratory stridor, nasal swelling, and epistaxis (39).

Although antibodies and humoral immunity have a role in tissue damage, cell-mediated immunity is also active and cytokine release plays an important role in cartilage destruction. T-cell clones directed against type-II collagen in a patient with RPC revealed activation of T cells resulting in production of Th1 cytokines including interferon $\gamma$ and tumor necrosis factor alpha (TNF $\alpha)$ (39). These results suggest a role for $\mathrm{T}$-cell clones in the pathogenesis of RPC and reinforce type-II collagen as a possible autoantigen in RPC (39). Other Th1 cytokines, to include monocyte chemoattractant protein 1 , macrophage inflammatory protein $1 \beta$, and interleukin- 8 , are elevated in RPC patients (31). TNF $\alpha$, in vitro, increases the synthesis of matrix degrading proteinases from chondrocytes and indirectly leads to cell damage $(39,41)$. This cytokine milieu results in inflammation and damage of chondrocytes and retards cartilage repair mechanisms. A unifying theory suggests an insult to the cartilage, exposing chondrocyte epitopes leading to cytokine release, local inflammation, and subsequent autoantibody production in a genetically predisposed host (8).

\section{Laboratory and Histologic Findings}

The diagnosis of RPC is typically established on clinical criteria alone, and the contribution of laboratory findings to diagnosis is limited. However, elevations in ESR or C-reactive protein, leukocytosis, thrombocytosis, and anemia of chronic disease can help gauge the activity and severity of disease. Urinary type-II collagen neoepitope, reflecting collagenase cleavage products of type-II collagen, has been suggested for monitoring disease activity but this is not currently used in clinical practice (42).

Autoantibodies, typically associated with other connective tissue diseases, may be found in patients with RPC but the significance of these is unclear. Antinuclear antibodies are reported in 20 to $60 \%$ of cases and are usually of a homogenous or speckled pattern on immunofluorescence (43). Patients typically will not have antibodies to double-stranded DNA, Sm, SSA (Ro), or SSB (La). ANCAs without specificity to proteinase-3 or myeloperoxidase have been described in some patients with RPC $(3,43)$. Patients also may have positive rheumatoid factor, a false positive rapid plasmin reagin (RPR), or positive antiphospholipid antibodies $(43,44)$.

Only 30 to $60 \%$ of patients with RPC are found to have anti-type-II collagen antibodies $(10,34,44)$. Type-II collagen antibodies target native or denatured type-II collagen and proteoglycans (43). In some cases these antibodies may be pathogenic, whereas in others they are present with cartilage damage (42). They are more likely to be present during disease activity and may correlate with disease severity (4). A case report by Matsumoto et al. reported a decline in anti-type-II collagen antibody titer with symptom improvement following steroid ther- apy (36). Cartilage-specific antibodies, including antitype-I, -IX, and -XI, have also been reported in association with RPC, but usually occur in conjunction with antitype-II collagen antibodies. Rarely, antibodies to matrillin- 1 are found in patients with RPC and tend to correlate with respiratory symptoms (40). The usefulness of anticollagen antibodies in the diagnosis and disease monitoring of RPC requires additional study.

Histologic examination of cartilage affected by RPC has characteristic changes. First, there is a loss of the basophilic staining, corresponding to decrease proteoglycan content as well as a reduction in the number of chondrocytes. Second, CD4 lymphocytes, polymorphonuclear cells, macrophages, and plasma cells infiltrate and deposit at the chondrodermal junction causing vacuolar degeneration and cartilage disruption with granulation tissue formation $(4,43,46)$. Finally, there is complete disruption of the normal architecture of cartilage and subsequent fibrosis, and occasional calcification or ossification (4). Immunofluorescence studies show the presence of immunoglobulin and C3 complement deposits along the chondrofibrous junction and in the perichondral vessel walls.

\section{Prognosis}

Overall survival at 17 years is reported to be $90 \%$ (47). The leading cause of mortality in RPC is pneumonia resulting from airway obstruction. Other causes of death include respiratory failure or progressive cardiovascular involvement. Predictors of a poor prognosis in patients younger than 51 include saddle nose deformity, arthritis, laryngotracheal involvement, systemic vasculitis, and hematuria. In older patients anemia predicts a worse outcome (48). We did not have any deaths during the course of our study and 2 patients were able to taper off of immunosuppressive therapy without flares for a period of 2 years.

\section{Differential Diagnosis}

The differential diagnosis may vary based on organ involvement. Auricular chondritis is relatively unique to $\mathrm{RPC}$ with sparing of the lobule. This similar presentation can occur with infectious perichondritis; however, the lobule is typically involved. Pathogens implicated include Pseudomonas aeruginosa or Staphylococcus aureus, fungal and anaerobic or polymicrobial infection (45). Auricular deformities may also be caused by leprosy, leishmaniasis, trauma, and frostbite.

The differential diagnosis of a saddle nose deformity includes trauma, leprosy, congenital syphilis, septal hematoma, perforation of the nasal septum because of cocaine use, sarcoidosis, and Wegener's granulomatosis (WG). Ocular inflammation can be associated with infection, rheumatoid arthritis, WG, polyarteritis nodosa, sarcoidosis, Behçet's disease, SLE, and seronegative spondyloarthropathies. Respiratory tract involvement may be confused with asthma or bronchitis clinically. Tracheal 
stenosis may occur in WG, sarcoidosis, or amyloidosis (48). Aortic aneurysm formation can occur from vasculitis (giant cell arteritis, Takayasu's disease, or Behçet's disease), infection (syphilis), spondyloarthropathies, and genetic diseases (Marfan's and Ehlers-Danlos syndrome) $(4,48)$.

The primary mimicker of RPC is WG. WG can cause ocular inflammation, epistaxis with nasal septal perforation, polyarticular arthritis, and auricular inflammation with sensorineural hearing loss, vertigo, and tinnitus. Features that differentiate WG from RPC include sinusitis, parenchymal lung disease, mononeuritis multiplex, granuloma formation on biopsy, and antibodies to c-ANCA with PR3 antibody specificity.

\section{Treatment}

There is no consensus on the treatment of RPC based on the medical literature. The majority of data is extracted from case reports and management is adapted to disease severity. A literature review provided treatment options based on disease severity and organ involvement. In 1 case, colchicine and indomethocin were effective as steroid-sparing therapies in a patient with refractory auricular chondritis and episcleritis who had failed azathioprine $(49,50)$. However, most patients described in the literature were treated with varying doses of corticosteroids as first-line therapy and other DMARDs or biologics were initiated in an attempt to taper the corticosteroid dosage and maintain remission.

The most commonly used adjunctive DMARD was methotrexate. Trentham and Le report on 31 patients with RPC who received methotrexate therapy; 23 were able to taper their prednisone dosage down from 19 to 5 mg daily and continued on methotrexate $17.5 \mathrm{mg}$ weekly (47). Seventeen additional cases, manifested by auricular, nasal, ocular, and tracheal involvement, demonstrated a beneficial response to methotrexate (24,31,51-56). Azathioprine was the second most common DMARD used as a steroid-sparing agent or following methotrexate failure $(5,51)$. Cyclosporin A is mentioned as a therapeutic option for RPC following failure of other therapies, but is rarely used because of its unfavorable side effect profile (8,47,56-58). Cyclophosphamide is reserved for severe organ or life-threatening disease, such as vasculitis, necrotizing scleritis, or laryngotracheal involvement $(4,9,31,47)$. There was 1 case report with a successful response to leflunomide in a patient with isolated auricular chondritis (59). In another case, mycophenolate mofetil successfully treated auricular chondritis in a patient who had failed NSAIDs, colchicine, dapsone, and methotrexate (60).

After traditional DMARD and corticosteroid failure, clinicians have tried biologics to control disease activity. A recent review of biologic use in RPC by Lepka et al. revealed 62 cases of RPC treated with biologic therapy reported in the literature (61). Infliximab was the most commonly used biologic in 31 cases. Fourteen of the patients treated with infliximab had rapid improvement in chondritis (auricular, nasal, laryngotracheal), scleritis, or vascular lesions (41,61-66). Etanercept was successfully administered in 8 patients and improved chondritis, scleritis, and tracheomalacia $(61,67,68)$. Adalimumab use has been reported in 4 patients and successfully treated 2 patients with chondritis, arthritis, scleritis, and laryngotracheal involvement $(43,61,69,70)$. Eleven patients have responded to rituximab; 9 of those patients were fully responsive and 2 were partially treated after failing other traditional DMARDs and anti-TNF $\alpha$ agents $(61,71,72)$. Anakinra has been described in 4 patients and controlled 3 patients with auricular, laryngotracheal disease, arthritis, and scleritis $(61,73,74)$. Tocilizumab treatment has been effective for 2 RPC patients $(61,75)$ and abatacept was successfully used in a 1 case reducing the frequency of RPC flares $(61,76)$.

\section{Medical Treatment of Mild-Moderate Disease}

Medical treatment is helpful for resolution of symptoms in mild to moderate RPC and slows the progression of severe life-threatening disease. Treatment of mild disease without organ damage including acute isolated auricular chondritis, mild nasal chondritis, episcleritis, diffuse anterior scleritis, and arthritis typically respond to NSAIDs, colchicine, or dapsone $(3,57,58)$. A short course of corticosteroids (10 to $20 \mathrm{mg}$ ) can often quickly resolve mild to moderate disease (4). In our study, mild disease was primarily managed with NSAIDs, dapsone, low-dose corticosteroids, and methotrexate.

\section{Medical Treatment of Severe Disease}

The management of acute, severe RPC requires high-dose corticosteroids $(1 \mathrm{mg} / \mathrm{kg} / \mathrm{d})$ with the addition of a steroidsparing agent. For sensorineural hearing loss or vestibular symptoms, initial high-dose corticosteroids are required (3). Sensorineural hearing loss tends to respond to aggressive therapy, whereas vestibular sequelae may be irreversible. More severe ocular disease will require high-dose corticosteroids in conjunction with a second-line agent (cyclophosphamide, azathioprine, methotrexate, cyclosporine $\mathrm{A}$, or antiTNF $\alpha$ agent) $(63,65,70,74,77)$, as corticosteroids are tapered. The drug of choice for necrotizing scleritis is cyclophosphamide $(9,77)$. There are 11 case reports of therapy with ritixumab for refractory auricular/nasal chondritis, but only 1 patient had a complete clinical response $(71,72)$. In addition, there is a single case report using anakinra for refractory auricular chondritis, ocular inflammation, and arthritis with success (73) and a single case report using intravenous immunoglobulin for refractory scleritis (78). The initial treatment of renal disease is high-dose corticosteroids, but crescentic disease is treated with cyclophosphamide (oral or intravenous). Some success has been reported with plasmapheresis as a last resort therapy in crescentic glomerulonephritis secondary to RPC $(25,79)$. The acute management of 
CNS involvement is with corticosteroids, and second-line agents are reserved (azathioprine) for refractory disease $(3,29,80)$. Overall, patients in our study with severe disease were managed with corticosteroids, mycophenolate mofetil, azathioprine, and biologics.

\section{Medical and Surgical Management of Laryngotracheal Involvement}

Medical management of laryngotracheal involvement in RPC begins with high-dose corticosteroids (1 mg/ $\mathrm{kg} / \mathrm{d}$ ) to decrease the severity of flares but also to limit disease progression. The common steroid-sparing, second-line agents include cyclophosphamide, mycophenolate mofetil, TNF $\alpha$ antagonists, methotrexate, or azathioprine $(25,43,45,47,63,65,67,81)$. Patients with tracheobronchomalacia tend to have a worse prognosis and suffer from increased symptoms and recurrent infections. These patients warrant early aggressive surgical therapy to include tracheobronchial stenting, external airway splinting, balloon dilation, intralesional corticosteroid injection, tracheostomy, or laryngotracheal reconstruction (11).

Stenting remains a key surgical intervention in the management of complicated airway disease in RPC. There are several types of airway stents available to include self-expandable metallic stents, Dumon silicone stent, dynamic stents, and the TM stent. The benefits of metallic stents include that they are easy to place via bronchoscopy, are visible on plain radiographs, provide strong but dynamic expandability, rarely migrate, and undergo rapid epithelialization resulting in preservation of mucociliary function $(11,81)$. The significant concerns with metallic stents include that they are easily broken, can become narrowed from dried sputum and granulation tissue, and are difficult to remove without causing tissue damage; multiple stents may be required for a long area of stenosis $(11,81)$. Current recommendations include use of metallic stents for mild disease and use of TM or silicone stents for severe disease (81). Other procedural interventions for laryngotracheal disease in our patient population included laser tracheal dilation and intralesional corticosteroid injection. Patients in our study were managed medically primarily with corticosteroids, methotrexate, and anti-TNF $\alpha$ therapy.

A rare interventional option, which is reserved for severe and refractory disease, is tracheal reconstruction. Karaman et al. described this procedure in 3 patients using nasal septal and auricular cartilage (82). Two weeks postoperatively the patients were treated with dexamethasone and methotrexate. At 2 years none of the patients had suffered a disease flare.

Higher lesions, localized subglottic disease, or patients with acute respiratory compromise may require tracheostomy, similar to 2 of our patients $(11,12)$. Other patients in our study were treated with laser dilation and stent placement.

\section{Medical and Surgical Management of Cardiovascular Complications}

Cardiovascular complications of RPC are the second most common cause for mortality after laryngotracheal involvement (22). Aortitis/vasculitis should be managed early with high-dose corticosteroids with the addition of a second-line agent after steroid tapering. Additional agents used in the management of inflammatory vascular disease include methotrexate, cyclophosphamide, azathioprine, chlorambucil, cyclosporine, and mycophenolate mofetil. There have been case reports using adalimumab and infliximab with success $(41,43,69)$.

Surgical intervention should be considered for aneurysmal dilatation or aortic valve disease that is identified as severe or symptomatic $(22,83)$. The Bentall-type procedure is recommended for replacement of the aortic valve, aortic root, and ascending aorta with composite graft, and reimplantation of the coronary arteries (22). In patients without aortic root involvement, it is recommended not to resect diseased tissue as it can lead to an increased risk of aortic root aneurysm. Common postoperative complications of the Bentall procedure include prosthetic dehiscence and perivalvular leakage (22). There is insufficient information in the literature to comment on mitral valve replacement. Following the Bentall procedure, therapy with immunosuppressive agents is recommended with short-term corticosteroids and prompt initiation of a second-line agent. The addition of a second-line agent is preferred because corticosteroids increase the risk for mediastinitis and congestive heart failure and do not systematically prevent dehiscence (22). The length of therapy following intervention remains controversial but a period of 2 to 5 years has been suggested (22). In our study 1 patient with an aortic aneurysm required surgical repair, and other patients had mild valvular disease, which was managed medically.

The strengths of our study lie in the ability to characterize features of RPC, an uncommon disease, in a large population representative of patients in North America. The incidence of disease and pattern of organ involvement seen in our study were reflective of that reported in other patient populations. Our study patients had a wide age range, varying degree of disease severity, and concomitant autoimmune disease.

Our study has several potential limitations common to retrospective reviews. There is the possibility of reviewer bias; however, the majority of data collection was gathered by the primary author using a standardized method and diagnostic criteria. The patient information contained within the EMR is dependent on clinician documentation of patient symptoms, therapies, and scanning of reports. Because ICD-9 codes were used, some patients may have been missed if they were coded incorrectly as having another disease. Another potential concern is a failure to capture all $\mathrm{DoD}$ beneficiary patients diagnosed with RPC, if they had been deferred to specialty network providers without access or documentation in our EMR. 
RPC can affect individuals of all age groups ranging from young children to elderly adults. Although the majority of our cases were in older individuals, $23 \%$ occurred in active duty soldiers. The presence of RPC in our active duty military population affects future deployment and disability.

The extent of organ involvement must be determined at baseline in RPC patients, as cardiac lesions and tracheobronchial involvement may be asymptomatic at presentation. Baseline evaluation of the cardiovascular system should include a thorough examination, EKG, and, if indicated, echocardiogram. All patients should have baseline PFTs with FVLs and a chest radiograph to assess for tracheobronchial involvement; any relevant abnormalities should be evaluated with an expiratory CT scan. There is no consensus on how often these monitoring tests and images should be reassessed. The authors recommend at least an annual screening EKG and PFTs with FVLs. Any significant cardiovascular abnormalities should be pursued with echocardiogram or relevant imaging modalities as necessary.

\section{REFERENCES}

1. Jaksch-Wartenhorst R. Polychondropathia. Wien Arch Intern Med 1923;6:93-100.

2. Pearson CM, Kline HM, Newcomer VD. Relapsing polychondritis. N Engl J Med 1960;263:51-8.

3. Kent P, Michet C, Luthra H. Relapsing polychondritis. Curr Opin Rheumatol 2003;16:56-61.

4. Letko E, Zafirakis P, Baltatzis S, Voudouri A, Livir-Rallatos C, Foster CS. Relapsing polychondritis: A clinical review. Semin Arthritis Rheum 2002;31(6):384-95.

5. McAdam LP, O’Hanlan MA, Bluestone R, Pearson CM. Relapsing polychondritis: Prospective study of 23 patients and a review of the literature. Medicine (Baltimore) 1976;55:193-215.

6. Michet CJ Jr, McKenna CH, Luthra HS, O'Fallon WM. Relapsing polychondritis. Survival and predictive role of early disease manifestations. Ann Intern Med 1986;104:74-8.

7. Damiani JM, Levine HL. Relapsing polychondritis-report of ten cases. Laryngoscope 1979;89:929-44.

8. Lahmer T, Treiber M, von Werder A, Foerger F, Knopf A, Heemann U, et al. Relapsing polychondritis: An autoimmune disease with many faces. Autoimmun Rev 2010;9:540-6.

9. Chow MT, Anderson SF. Relapsing polychondritis. Optom Vis Sci 2000;77(6):286-92.

10. Bachor E, Blevins NH, Karmody C, Kühnel T. Otologic manifestations of relapsing polychondritis. Review of literature and report of nine cases. Auris Nasus Larynx 2006;33:135-41.

11. Sarodia BD, Dasgupta A, Mehta AC. Management of airway manifestations of relapsing polychondritis: Case reports and review of literature. Chest 1999;116:1669-75.

12. Ernst A, Rafeq S, Boiselle P, Sung A, Reddy C, Michaud G, et al. Relapsing polychondritis and airway involvement. Chest 2009; 135:1024-30.

13. Eng J, Sabanathan S. Airway complications in relapsing polychondritis. Ann Thorac Surg 1991;51(4):686-92.

14. Mohammad A, Ambrose N, Tuohy M, Conway R, Costello R, Kearns G. Relapsing polychondritis: Reversible airway obstruction or asthma. Exp Rheum 2008;26:938-40.

15. Lee C, Singer A. Respiratory failure due to subglottic stenosis from relapsing polychondritis. J Emerg Med 2006;2(18):750-2.

16. Lin ZQ, Xu JR, Chen JJ, Hua XL, Zhang KB, Guan YJ. Pulmonary CT findings in relapsing polychondritis. Acta Radiol 2010;5:522-6.
17. Lee KS, Ernst A, Trentham DE, Lunn W, Feller-Kopman DJ, Boiselle PM. Relapsing polychondritis: Prevalence of expiratory CT airway abnormalities. Radiology 2006;240(2):565-73.

18. Heman-Ackah YD, Remley KB, Goding GS. A new role for magnetic resonance imaging in the diagnosis of laryngeal relapsing polychondritis. Head Neck 1999;21:484-9.

19. Mohsenifar Z, Tashkin DP, Carson SA, Bellamy PE. Pulmonary function in patients with relapsing polychondritis. Chest 1982; 81(6):711-7.

20. Krell WS, Staats BA, Hyatt RE. Pulmonary function in relapsing polychondritis. Am Rev Respir Dis 1986;133(6):1120-3.

21. Segel MJ, Godfrey S, Berkman N. Relapsing polychondritis: Reversible airway obstruction is not always asthma. Mayo Clin Proc 2004;79:407-9.

22. Dib C, Moustafa SE, Mookadam M, Zehr KJ, Michet CJ, Mookadam F. Surgical treatment of the cardiac manifestations of relapsing polychondritis: Overview of 33 patients identified through literature review and the Mayo Clinic records. Mayo Clin Proc 2006;81(6):772-6.

23. Del Rosso A, Petix NR, Pratesi M, Bini A. Cardiovascular involvement in relapsing polychondritis. Semin Arthritis Rheum 1997; 26(6):840-4.

24. Hojaili B, Keiser H. Relapsing polychondritis presenting with complete heart block. J Clin Rheum 2008;14:24-6.

25. Chang-Miller A, Okamura M, Torres VE, Michet CJ, Wagoner $\mathrm{RD}$, Donadio JV, et al. Renal involvement in relapsing polychondritis. Medicine (Baltimore) 1987;66(3):202-17.

26. Francès C, El Rassi R, LaPorte JL, Rybojad M, Papo T, Piette JC. Dermatologic manifestations of relapsing polychondritis. A study of 200 cases at a single center. Medicine (Baltimore) 2001;80:173-9.

27. Hsu KC, Wu YR, Lyu RK, Tang LM. Aseptic meningitis and ischemic stroke in relapsing polychondritis. Clin Rheum 2006; 25:265-7.

28. Sampaio L, Silva L, Mariz E, Ventura F. Central nervous system involvement in relapsing polychondritis. Joint Bone Spine 2010; 77:619-20.

29. Yang SM, Chou CT. Relapsing polychondritis with encephalitis. J Clin Rheum 2004;10:83-5.

30. Papo T, Wechsler B, Bletry O, Piette A-M, Godeau P, Piette J-C. Pregnancy in relapsing polychondritis. Arthritis Rheum 1997; 40(7):145-9.

31. Ananthakrishna R, Goel R, Padhan P, Mathew J, Danda D. Relapsing polychondritis-case series from South India. Clin Rheum 2009;28(Suppl 1):s7-10.

32. Stabler T, Piette JC, Chevalier X, Marini-Portugal A, Kraus VB. Serum cytokine profiles in relapsing polychondritis suggest monocyte/macrophage activation. Arthritis Rheum 2004;50(11):3663-7.

33. Keller E, Yao Z, Volgger A, Lang B, Albert ED. A novel variant of DR4 (DRB1*0421) identified in a patient with polychondritis. Immunogenetics 1995; 41(2-3):171.

34. Hue-Lemoine S, Caillat-Zucman S, Amoura Z. HLA-DQA1 and DQB1 alleles are associated with susceptibility to relapsing polychondritis: From transgenic mice to humans. Arthritis Rheum 1999;42(2):261-3.

35. Anstey A, Mayou S, Morgan K, Clague RB, Munro DD. Relapsing polychondritis: Autoimmunity to type II collagen and treatment with cyclosporin A. Br J Dermatol 1991;125:588-91.

36. Ormerod AD, Clark LJ. Relapsing polychondritis-treatment with cyclosporin A. Br J Dermatol 1992;127:300-1.

37. Matsumoto $Y$, Imanaga $T$, Kawajiri $T$, Ominami $S$, Ito $T$, Hayashi T, et al. Measurement of anti-type II collagen antibody diagnosis and follow-up useful in a case of relapsing polychondritis. Nihon Kokyuki Gakkai Zasshi 2002;40(1):45-9.

38. Cremer MA, Pitcock JA, Stuart JM, Kang AH, Townes AS. Auricular chondritis in rats. An experimental model of relapsing polychondritis induced with type II collagen. J Exp Med 1981; 154:535-9.

39. Buckner JH, Van Landeghen M, Kwok WW, Tsarknaridis L. 
Identification of type II collagen peptide 261-273-specific T cell clones in a patient with relapsing polychondritis. Arthritis Rheum 2002;46(1):238-44.

40. Hansson AS, Heinegård D, Piette JC, Burkhardt H, Holmdahl R. The occurrence of autoantibodies to matrilin 1 reflects a tissuespecific response to cartilage of the respiratory tract in patients with relapsing polychondritis. Arthritis Rheum 2001;44(10): 2402-12.

41. Marie I, LaHaxe L, Josse S, Levesque H. Sustained response to infliximab in a patient with relapsing polychondritis with aortic involvement. Rheumatology (Oxford) 2009;48:1328-9.

42. Kraus VB, Stabler T, Le ET, Saltarelli M, Allen NB. Urinary type II collagen neoepitope as an outcome measure for relapsing polychondritis. Arthritis Rheum 2003;48(10):2942-8.

43. Lahmer T, Knopf A, Treiber M, Heemann U, Thuermel K. Treatment of relapsing polychondritis with the TNF-alpha antagonist adalimumab. Clin Rheumatol 2010;29:1331-4.

44. Balsa-Criado A, Gonzalez-Hernandez T, Cuesta MV, Aguado P, Garcia S, Gijon J. Lupus anticoagulant in relapsing polychondritis. J Rheumatol 1990;17(10):1426-7.

45. Butterton JR, Collier DS, Romero JM, Zembowicz A. Case records of the Massachusetts General Hospital. Case 14-2007. A 59-year-old man with fever and pain and swelling of both eyes and the right ear. N Engl J Med 2007;356:1980-8.

46. Spadaro A, Taccari E, Zoppini A. A case of relapsing polychondritis: Pathogenetic considerations. Clin Exp Rheumatol 1988; 6(1):95-6.

47. Trentham DE, Le CH. Relapsing polychondritis. Ann Intern Med 1998;129:114-22.

48. Piette JC, El-Rassi R, Amoura Z. Antinuclear antibodies in relapsing polychondritis. Ann Rheum Dis 1999;58(10):656-7.

49. Mark KA, Franks AG. Colchicine and indomethacin for the treatment of relapsing polychondritis. J Am Acad Dermatol 2002; 46(Suppl 2):S22-4.

50. Bhat A, Naguwa SM, Cheema GS, Gershwin ME. Colchicine revisited. Ann NY Acad Sci 2009;1173:766-73.

51. Belot A, Duquesne A, Job-Deslandre C, Costedoat-Chalumeau N, Boudjemaa S, Wechsler B, et al. Pediatric-onset relapsing polychondritis: Case series and systematic review. J Pediatr 2010; 156(3):484-9.

52. Soto-Romero I, Fustes-Morales AJ, De Leon-Bojorge B, Contreras-Ruiz J, Ruiz-Maldonado R. Relapsing polychondritis: A pediatric case. Pediatr Dermatol 2002;19(1):60-3.

53. Park J, Gowin KM, Schumacher HR. Steroid sparing effect of methotrexate in relapsing polychondritis. J Rheumatol 1996;23:937-8.

54. Kong KO, Vasoo S, Tay NS, Ching HH. Relapsing polychondritis-An Oriental case series. Singapore Med J 2003;44(4):197-200.

55. Edrees A. Relapsing polychondritis: A description of a case and review article. Rheumatology Int 2011;31:707-13.

56. Gergley P, Poor G. Relapsing polychondritis. Best Pract Res Clin Rheumatol 2004;18(5):732-8.

57. Rapini RP, Warner NB. Relapsing polychondritis. Clin Dermatol 2006;24:482-5.

58. Mishriki YY. Puzzles in practice. Relapsing polychondritis (RPC). Postgrad Med 2010;122(4):224-6.

59. Handler RP. Leflunomide for relapsing polychondritis: Successful long-term treatment. J Rheumatol 2006;33(9):1916.

60. Goldenberg G, Sangueza O, Jorizzo J. Successful treatment of relapsing polychondritis with mycophenolate mofetil. J Dermatol Treat 2006;17:158-9.

61. Lekpa FK, Kraus VB, Chevalier X. Biologics in relapsing polychondritis: A literature review. Semin Arthritis Rheum 2011 [Epub ahead of print].

62. Soares de Barrio AP, Nakamura NA, Santana T, Santos Motta JQ, Bianchi W. Infliximab in relapsing polychondritis. Bras. J Rheumatol 2010;50(2):211-6.
63. Mpofu S, Estrach C, Curtis J, Moots RJ. Treatment of respiratory complications in recalcitrant relapsing polychondritis with infliximab. Rheumatol 2003;42:1117-8.

64. Richez C, Dumoulin C, Coutouly X, Schaeverbeke T. Successful treatment of relapsing polychondritis with infliximab. Clin Exp Rheumatol 2004;22:629-31.

65. Saadoun D, Deslandre CJ, Allanore Y, Pham XV, Kahan A, Kahan A. Sustained response to infliximab in 2 patients with refractory relapsing polychondritis. J Rheumatol 2003;30(6):1394-5.

66. Bell D, Wright D, Witt PD. Durability of nasal reconstruction in an adolescent with relapsing polychondritis treated with infliximab. Plast Reconstr Surg 2007;120(4):1087-8.

67. Subrahmanyam P, Balakrishnan C, Dasgupta B. Sustained response to etanercept after failing infliximab, in a patient with relapsing polychondritis with tracheomalacia. Scand J Rheumatol 2008;37(3):239-40.

68. Carter JD. Treatment of relapsing polychondritis with a TNF antagonist. J Rheumatol 2005;32(7):1413.

69. Seymour MW, Home DM, Williams RO, Allard SA. Prolonged response to anti-tumour necrosis factor treatment with adalimumab (Humira) in relapsing polychondritis complicated by aortitis. Rheumatol (Oxford) 2007;46(11):1738-9.

70. McCarthy E, Cunnane G. Treatment of relapsing polychondritis in the era of biological agents. Rheumtol Int 2010;30:827-8.

71. Leroux G, Costedoat-Chalumeau N, Brihaye B, Cohen-Bittan J, Amoura Z, Haroche J, et al. Treatment of relapsing polychondritis with rituximab: A retrospective study of nine patients. Arthritis Rheum 2009;61(5):577-82.

72. Ratzinger G, Kuen-Spiegl M, Sepp N. Successful treatment of recalcitrant relapsing polychondritis with monoclonal antibodies. J Eur Acad Dermatol Venereol 2009;23:474-5.

73. Vounotrypidis P, Sakellariou GT, Zisopoulos D, Berberidis C. Refractory relapsing polychondritis: Rapid and sustained response in the treatment with an IL-1 receptor antagonist (anakinra). Rheumatol. (Oxford) 2006;45(4):491-2.

74. Buonuomo PS, Bracaglia C, Campana A, El Hachem M, Diociaiuti A, Insalaco A, et al. Relapsing polychondritis: New therapeutic strategies with biological agents. Rheumatol Int 2010;30:691-3.

75. Kawai M, Hagihara K, Hirano T, Shima Y, Kuwahara Y, Arimitsu J, et al. Sustained response to tocilizumab in two patients with refractory relapsing polychondritis. Rheumatol (Oxford) 2009;48:318-9.

76. Guillaume M, Laurent S, Leonardo A, Philippe A. Abatacept for relapsing polychondritis. Rheumatol 2010;49:1019.

77. Foster CS, Rice BA. Scleritis in relapsing polychondritis. Response to therapy. Ophthalmology 1990;97(7):892-8.

78. Terrier B, Aouba A, Bienvenu B, Bloch-Queyrat C, Delair E, Mallet J, et al. Complete remission in refractory relapsing polychondritis with intravenous immunoglobulins. Clin Exp Rheum 2007;25:136-8, 178.

79. Botey A, Navasa M, del Olmo A, Montoliu J, Ferrer O, Cardesa A, et al. Relapsing polychondritis with segmental necrotizing glomerulonephritis. Am J Nephrol 1984;4(6):375-8.

80. Hsu Kai-Cheng, Wu YR, Lyu RK, Tang LM. Aseptic meningitis and ischemic stroke in relapsing polychondritis. Clin Rheumatol 2006;25:265-7.

81. Nakajima T, Sekine Y, Yasuda M, Yasufuku K, Iyoda A, Suzuki M, et al. Long-term management of polychondritis with serial tracheobronchial stents. Ann Thorac Surg 2006;81:e24-26.

82. Karaman E, Duman C, Cansz H, Ylmaz M, Ibrahimov M. Laryngotracheal reconstruction at relapsing polychondritis. J Craniofac Surg 2010;21:211-2.

83. Lang-Lazdunski L, Hvass U, Paillole C, Pansard Y, Langlois J. Cardiac valve replacement in relapsing polychondritis. A review. J Heart Valve Dis 1995;4(3):227-35. 